\title{
Skin Care and Synbiotics for Prevention of Atopic Dermatitis or Food Allergy in Newborn Infants: A $2 \times 2$ Factorial, Randomized, Non-Treatment Controlled Trial
}

\author{
Eishika Dissanayake ${ }^{a}$ Yumi Tani $^{\text {b Kazue Nagaic }{ }^{c} \text { Masumi Saharab }}$

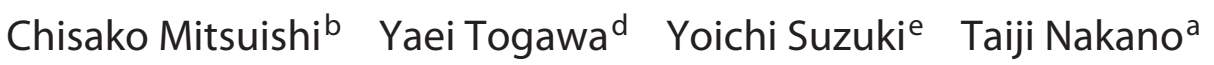 \\ Fumiya Yamaide $^{a}$ Hiroshi Ohno $^{f}$ Naoki Shimojo $^{a}$

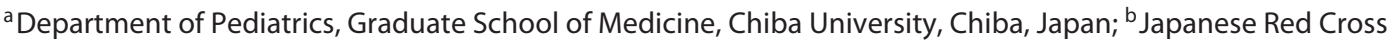 \\ Katsushika Maternity Hospital, Tokyo, Japan; ' Research and Education Center of Health Sciences, Gunma University \\ Graduate School of Health Sciences, Gunma, Japan; d Department of Dermatology, Graduate School of Medicine,

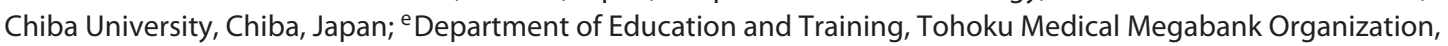 \\ Tohoku University, Tohoku, Japan; ${ }^{\mathrm{f}}$ RIKEN Center for Integrative Medical Sciences, Yokohama, Japan
}

\section{Keywords}

Atopic dermatitis · Infants · Prevention · Skin care ·

Synbiotics

\begin{abstract}
Background: Atopic dermatitis (AD) and food allergy (FA) are common childhood diseases, which may either be interrelated or be the result of skin barrier disruption and gut mucosal dysbiosis. Although some evidence suggests the efficacy of emollients and synbiotics, there is no conclusive evidence on the use of these interventions alone or in combination. Objectives: This study is aimed at identifying the efficacy of emollients and synbiotics in preventing AD and FA in children during the first year of life. Methods: The babies of mothers recruited prenatally received either an emollient, synbiotic, both or neither. The intervention was carried out from birth up to 6 months of age. The age of occurrence of $A D$ and FA were reported in multiple questionnaires at 1, 6, and 9 months and at 1 year of age. AD was diagnosed by a pediatrician at 9 months of age. Results: $A$ total
\end{abstract}

of 459 babies qualified for the outcome assessment at 1 year of age. Neither the emollient nor the synbiotic showed any effect on reducing the development of AD and FA at 1 year of age. Conclusions: This study did not provide any evidence to show that emollients and synbiotics, alone or in combination are sufficient to prevent the occurrence of AD or FA in children up to 1 year of age.

(c) 2019 S. Karger AG, Basel

\section{Introduction}

In recent years, allergic diseases have been increasing worldwide. Recent epidemiological studies have revealed the concept of the allergic march, starting from atopic dermatitis (AD) and food allergy (FA) to allergic rhinitis and bronchial asthma. Of these, AD is the earliest manifestation, and skin barrier abnormalities have

Edited by: H.-U. Simon, Bern.

\section{KARGER}

(c) 2019 S. Karger AG, Basel

E-Mail karger@karger.com

www.karger.com/iaa
Prof. Naoki Shimojo

Department of Pediatrics, Graduate School of Medicine

Chiba University, 1-8-1 Inohana, Chuo-ku

Chiba 260-8670 (Japan)

E-Mail shimojo@faculty.chiba-u.jp 
been suggested to play an important role in the initiation of FA.

The stratum corneum is the major component of the skin barrier and is responsible for maintaining the skin barrier function. Disruption of the lipid composition of the stratum corneum has been seen in lesional and nonlesional AD skin [1]. Several studies have explored the benefits of skin moisturizers that strengthen the lipid barrier in the prevention of $\mathrm{AD}$ in infancy. As moisturizing agents, products containing 3 kinds of lipid components (ceramide, cholesterol, and free fatty acids) for neonates have been shown to improve the skin barrier function [2]. A recent study also reported that application of a ceramide-dominant emollient for 6 months from birth showed a trend towards reducing the incidence of $\mathrm{AD}$ and food sensitization at 1 year of age and that the beneficial effects lasted for 6 months after cessation of treatment [3]. This suggests that skin emollients may be effective in preventing the development of $\mathrm{AD}$, but needs further evidence to prove a definite benefit.

In addition, factors that disrupt the normal post-natal colonization of the gut, such as Cesarean deliveries and the use of antibiotics, have been linked to the development of $\mathrm{AD}[1,4]$. A recent meta-analysis concluded that probiotics, defined as live microorganisms that, when administered in adequate doses, provide health benefits to the host [5], are indeed effective in the prevention of $\mathrm{AD}$ in neonates who received daily doses of lactobacilli alone or in combination with bifidobacteria [6]. At present, the World Allergy Organization - McMaster University Guidelines for Allergic Disease Prevention: Probiotics recommends the use of probiotics for pregnant women who are at high-risk of having children with AD [7]. Prebiotics are non-digestible food ingredients that beneficially affect the host by stimulating the growth and/or the activity of a limited number of bacterial species in the colon [8]. A study on a group of high-risk infants receiving a formula of fructo-oligosaccharides and galacto-oligosaccharides reported a borderline decrease in the development of $\mathrm{AD}$ with a significant increase in fecal bifidobacterial counts [9] while galacto-oligosaccharides alone did not [10]. A mixture of probiotic bacteria and prebiotics, known as synbiotics, has also been used to explore the effect on the prevention of $\mathrm{AD}$, and evidence suggests that synbiotics may be useful in the prevention of $\mathrm{AD}$ [11].

Although many interventional studies target either intestinal flora or skin barrier function, because of the many factors involved, it may not be possible to prevent the development of allergies by a single method and this may require a combination. Therefore, in this study we com- bined synbiotics and skin moisturizers to maximize the impact by assisting the establishment of normal flora prenatally and during early infancy and also by protecting the skin barrier through emollients to determine their combined effect on the development of AD.

\section{Materials and Methods}

Study Design (Fig. 1)

This was a $2 \times 2$ factorial, randomized, non-treatment controlled trial to evaluate the prevention of $\mathrm{AD}$ or FA by use of skin care and synbiotics in infants. The study was approved by the Chiba University Ethics Committee (reference no. 2067), and was registered at the University Hospital Medical Information Network (JPRN-UMIN000010838).

\section{Participants}

Pregnant women at 24-32 weeks of gestation, attending the ante-natal clinic at the Japanese Red Cross Katsushika Maternity Hospital in Tokyo, Japan were recruited into the study. Following delivery, the babies were recruited into the study if they met the following criteria:

\section{Inclusion criteria}

- Born at term

- Written informed consent available from parent(s)/guardian A family history of atopy was not required for inclusion.

\section{Exclusion criteria}

- Pre-term birth

- Complications due to severe underlying diseases

- HBV or HIV positivity of mother at the time of birth

- Any other inappropriate status as judged by the physician

The midwife completed a questionnaire before the mother and the baby were discharged from hospital. All subsequent examinations and collection of samples were done at the Japanese Red Cross Katsushika Maternity Hospital in Tokyo, Japan.

\section{Interventions}

The parents/caregivers were advised on how the interventions should be applied at home. Group 1 received a combination of synbiotics and skincare, group 2 received synbiotics only, group 3 received skincare only, and group 4 received no intervention.

The interventions were carried out from birth to 6 months of age and further observation was made for an additional 6 months. The parents/guardian maintained a diary for 6 months of the intervention, to record the number of times that the emollient was applied, any illnesses contracted during this period and the use of antibiotics during this time.

Skin Care

All participants receiving skin care (groups 1 and 3) were given Locobase ${ }^{\circledR}$ REPAIR Cream (Daiichi Sankyo, Japan) which contains ceramide, cholesterol, and free fatty acids. The parents/ guardians were instructed to apply emollient 2-3 times/day, after a bath or on clean skin, particularly on the cheeks and the peri-oral area. The parents/guardians were allowed to apply the emollient on other parts of the body at their discretion and were not advised 
Fig. 1. Flow chart depicting the study plan and follow-up. After 1 year of age, participants were followed up to 4 years of age.

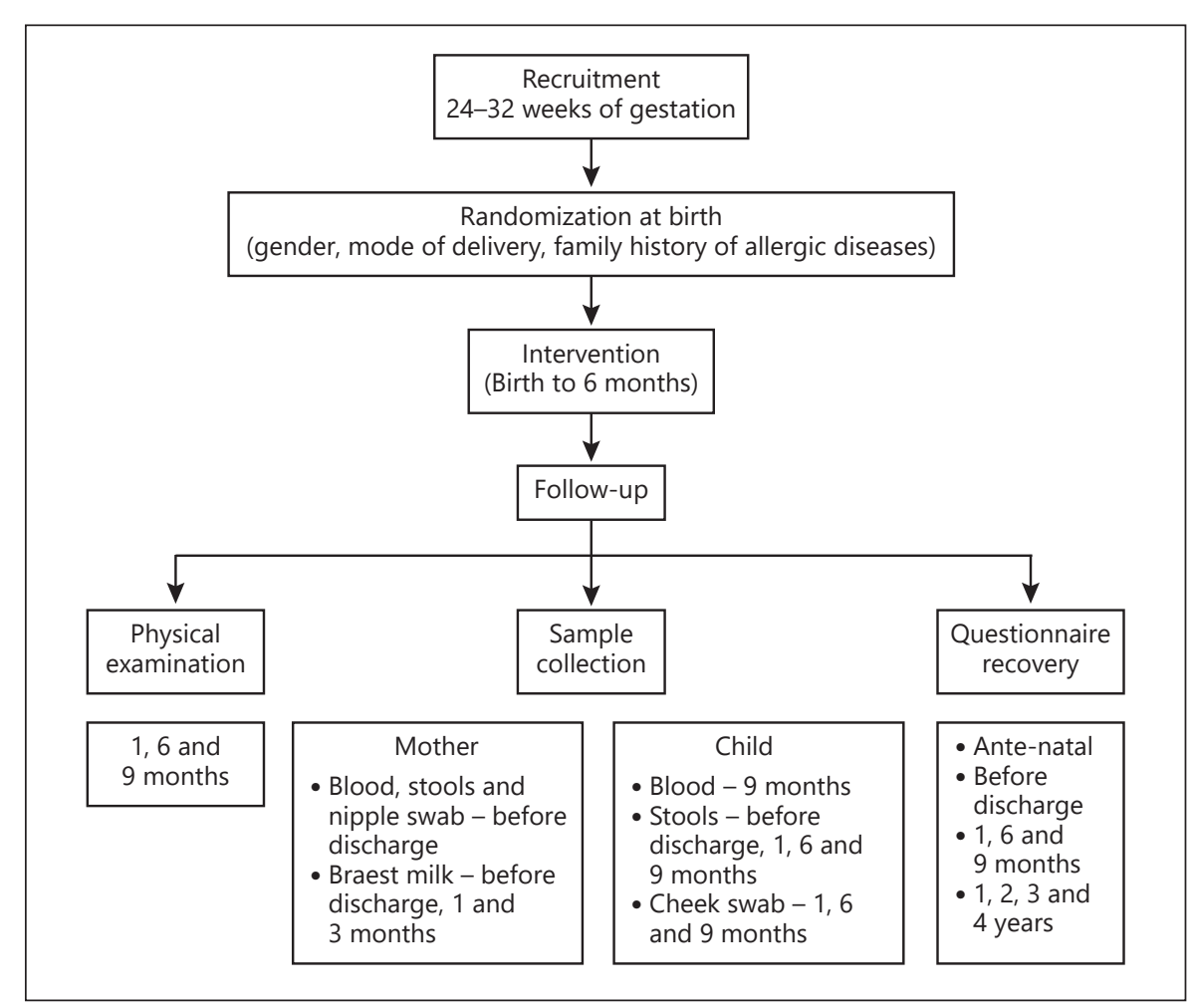

for or against it. The control group was not prevented from applying emollients due to ethical reasons. A diary was maintained to record the number of times and the amount of emollient that was applied each month.

Synbiotics

The groups that were given synbiotics (groups 1 and 2) received a combination of $0.5 \mathrm{~g}\left(7 \times 10^{9} \mathrm{CFU} / \mathrm{g}\right)$ of Bifidobacterium bifidum OLB6378 (Meiji Holdings Co. Ltd., Japan) combined with $0.5 \mathrm{~g}$ of fructo-oligosaccharides (Meiji Food Materia Co., Ltd., Japan) twice a day.

Skin Care and Synbiotics

The babies in this group were given both of the above.

\section{Outcomes}

Primary Outcome

The primary outcome assessed was the development of AD by 1 year of age.

$\mathrm{AD}$ was diagnosed according to the criteria of the Japanese Dermatological Association [12], when an itchy rash lasting 2 or more months was reported in the questionnaires returned at 1,6 , and 9 months and 1 year of the baby's age. In addition, AD was diagnosed using the U. K. Working Party's Diagnostic Criteria included in the questionnaire at 1 year [13-15].

Secondary Outcomes

- Prevalence of FA, as reported in the questionnaires at 1 year.

- Sensitization to food and/or inhalant allergens - total and allergen-specific IgE levels were determined in blood sampled at 9 months of age.
- EASI score - the babies were examined by Dr. YuT (pediatrician) at 9 months of age. If AD was diagnosed, the severity was determined using the EASI score and photography of the body was taken. AD diagnosis was further confirmed blindly by YaT (dermatologist) and NS (pediatrician). AD was diagnosed based on criteria of the Japanese Dermatological Association [12].

- Thymus and activation-regulated chemokine (TARC) score blood samples obtained at 9 months were used for evaluating the TARC levels in all participants.

\section{Sample Size}

A total of 800 patients with 200 patients per treatment arm, were required to enter the study considering feasibility. The sample size was calculated using log-rank test with normal approximation using a significance level of 0.05 (two-tailed). This meant that 74 patients were required per arm under the hypothesis that the expected value of the primary endpoint was $5 \%$ and the threshold value was $15 \%$. Two hundred and twenty seven patients were required by conservative estimation under the hypothesis that the expected value of primary endpoint was 5\% and the threshold value was $10 \%$ using log-rank test with normal approximation at a significance level of 0.05 (two-tailed). Two hundred patients per arm held $75 \%$ power to verify the hypothesis so that the expected value of primary endpoint was $5 \%$ and the threshold value was $10 \%$ using log-rank test with normal approximation.

\section{Randomization}

Intervention group allocation was determined by a randomization system based on the minimization technique (Nouvelle Place Inc., Tokyo, Japan). Babies born at term were randomized into 4 


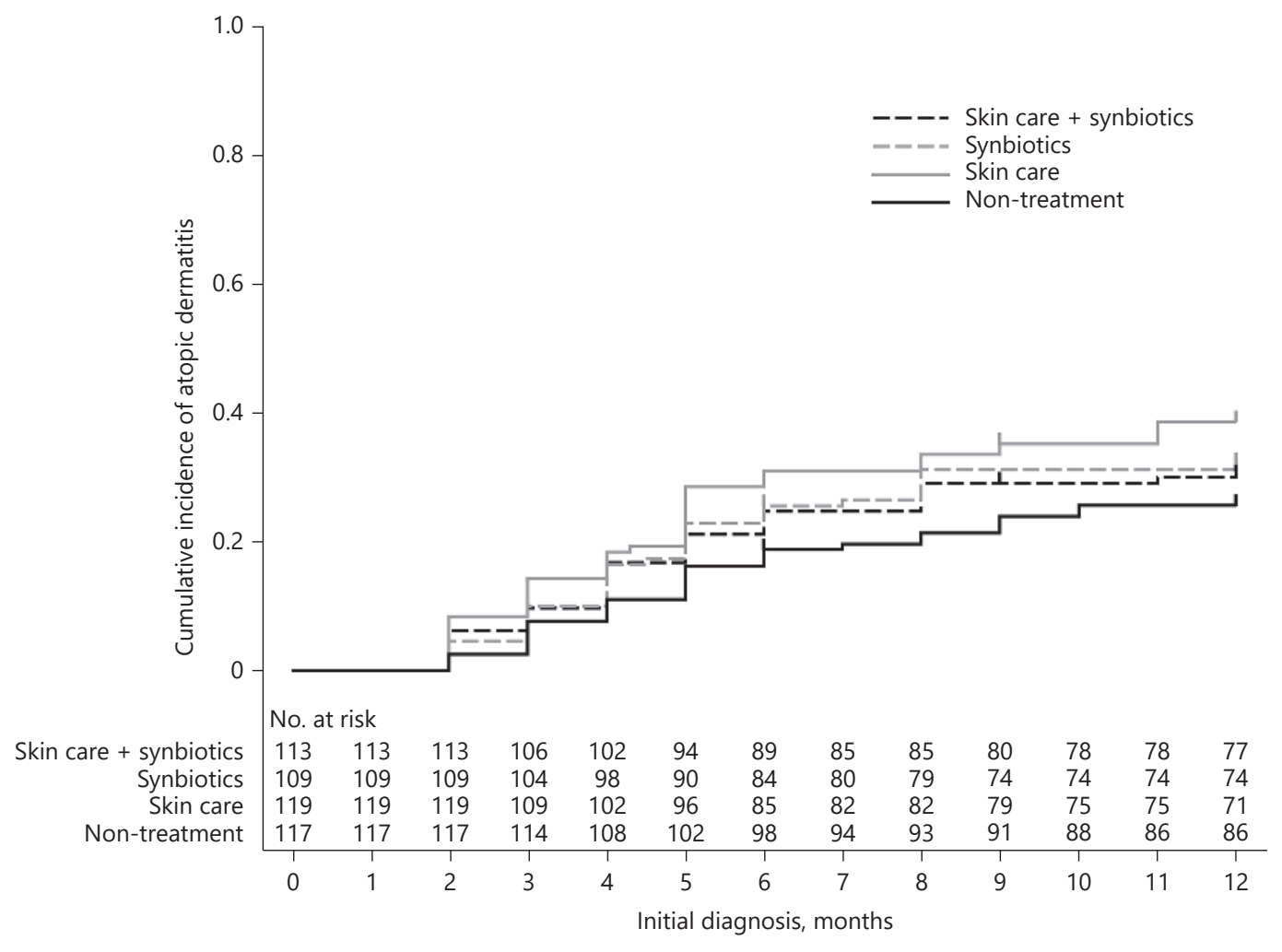

Fig. 2. Cumulative incidence of developing $\mathrm{AD}$ at 1 year of age.

groups according to gender (male or female), mode of delivery (vaginal or Caesarean) and family history of allergic diseases (present or absent) using computerized random numbers. Randomization was performed at a central location.

Statistical Methods

Subjects were included in the analysis population only if they did not fall into any of the following categories:

- Failure to fulfill recruitment criteria of research plan (consent not given, recruitment outside of recruitment period, etc.)

- Withdrawal of consent

- Data unavailable after randomization

The homogeneity of the treatment groups for patient characteristics was analyzed using ANOVA and adjusted using the Tukey-Kramer method for categorical data.

The primary endpoint was the incidence of $\mathrm{AD}$ up to 1 year of age. The primary endpoint was analyzed by using a closed testing procedure for multiple comparisons of treatment. In step 1, the log-rank test was performed to assess the incidence of AD between group 1 and group 4 . In step 2, the log-rank test was performed to assess the incidence of $\mathrm{AD}$ between groups 2, 3, and 4. Step 2 was done only if step 1 gave a significant result. If a significant difference was observed between groups 1 and 4, group 1 was considered valid.

For the primary analysis, the log-rank test was used to compare time-to-event curves in the 2 groups (group 1 and group 4). Prevalence of FA at 1 year and sensitization rates to food and in- halant allergens at 9 months were compared using ANOVA and adjusted using the Tukey-Kramer method. Holm's method was used to adjust for multiple testing for categorical data. All statistical tests were two-sided, and the nominal a level was 0.05. All analyses were performed using SAS ${ }^{\circledR}$ version 9.3 (SAS Institute, Cary, NC, USA).

\section{Results}

\section{Participant Characteristics}

A total of 605 pregnant women were recruited at 2432 weeks of gestation from the Japanese Red Cross Katsushika Maternity Hospital in Tokyo, Japan, between October 2012 and March 2014 (Fig. 2). It was intended to recruit 800 participants over the 2 years, but this target was not met at the end of the recruitment period. Of the recruited participants, 549 babies qualified to be randomized into skin care and synbiotics (group $1 ; n=137$ ), synbiotics only (group 2; $n=137$ ), skincare only (group 3 ; $n=138$ ), and no intervention groups (group $4 ; n=$ 137). They underwent the respective intervention/s for a period of 6 months. A total of 459 babies from the 4 
Table 1. Participant characteristics

\begin{tabular}{|c|c|c|c|c|}
\hline & $\begin{array}{l}\text { Skin care }+ \\
\text { synbiotics, } n(\%)\end{array}$ & $\begin{array}{l}\text { Synbiotics, } \\
n(\%)\end{array}$ & $\begin{array}{l}\text { Skin care, } \\
n(\%)\end{array}$ & $\begin{array}{l}\text { No intervention, } \\
n(\%)\end{array}$ \\
\hline \multicolumn{5}{|l|}{ Gender } \\
\hline Male & $55(48.7)$ & $55(50.5)$ & $59(49.2)$ & $56(47.9)$ \\
\hline Female & $58(51.3)$ & $54(49.5)$ & $61(50.8)$ & $61(52.1)$ \\
\hline \multicolumn{5}{|l|}{ Mode of delivery } \\
\hline Normal delivery & $77(68.1)$ & $70(64.2)$ & $83(69.2)$ & $79(67.5)$ \\
\hline Vacuum extraction & $7(6.2)$ & $12(11.0)$ & $11(9.2)$ & $12(10.3)$ \\
\hline Cesarean delivery & $27(23.9)$ & $26(23.9)$ & $25(20.8)$ & $25(21.4)$ \\
\hline Forceps delivery & $2(1.8)$ & $1(0.9)$ & $1(0.8)$ & $1(0.9)$ \\
\hline Breech delivery & $0(0.0)$ & $0(0.0)$ & $0(0.0)$ & $0(0.0)$ \\
\hline \multicolumn{5}{|l|}{ Family history of allergy } \\
\hline Absent & $15(13.3)$ & $17(15.6)$ & $18(15.0)$ & $26(22.2)$ \\
\hline Present & $98(86.7)$ & $92(84.4)$ & $102(85.0)$ & $91(77.8)$ \\
\hline Birth weight, $g$ & $3,028.99$ & $3,046.64$ & $3,055.97$ & $3,059.08$ \\
\hline Gestational age, weeks & 38.8 & 39 & 39 & 39.2 \\
\hline \multicolumn{5}{|l|}{ Exclusively breastfed } \\
\hline (up to 4 months of age) & $44(38.9)$ & $37(33.9)$ & $43(35.8)$ & $49(41.9)$ \\
\hline
\end{tabular}

groups completed the intervention and qualified for assessment of the primary outcome at 1 year of age. As shown in Table 1, the baseline characteristics were similar among the groups. Although the number of babies with no family history of allergic diseases in group 4 (no intervention; $22.2 \%$ ) was relatively higher than in the other groups, this difference was not significant. No adverse effects to the interventions were reported during the study period.

\section{Primary Outcome}

Of the 459 babies who were eligible for outcome assessment, $146(31.8 \%)$ developed $\mathrm{AD}$ at 1 year of age. The cumulative incidence of $\mathrm{AD}$ at 1 year of age in each group, defined as an itchy skin condition lasting 2 or more months, was $30.9 \%$ in group $1,32.1 \%$ in group 2 , $38.6 \%$ in group 3 , and $25.6 \%$ in group 4 (Table $2 a$ ). According to the U. K. Working Party's criteria included in the questionnaires returned at 1 year, the incidence of $\mathrm{AD}$ was $20.4 \%$ in group $1,14.7 \%$ in group $2,21.0 \%$ in group 3 , and $18.8 \%$ in group 4 (Table $2 \mathrm{~b}$ ). The incidences were not significantly different in favor of the interventions between the 4 groups according to both methods of diagnosis (Table 2c). One infant who received skin care and was diagnosed as having $\mathrm{AD}$ at 9 months and at 1 year was excluded from the Kaplan-Meier curve, as the time of onset of $\mathrm{AD}$ was unknown, but was included in other analyses where the time of onset was not considered.
Approximately $80 \%$ of the parents/guardians in the emollient groups reported that they applied the emollient at least twice a day. Adjusting for emollient application rate did not lead to a significant difference in the rate of $\mathrm{AD}$ development among the groups. The effect of emollient application was also investigated in all babies who received emollient (groups 1 and 3 ) versus those who did not (groups 2 and 4), but this too did not show any difference in the incidence of $\mathrm{AD}$.

\section{Secondary Outcomes}

The serum TARC levels and the EASI scores were evaluated as secondary outcomes. Table 3 a gives the mean TARC levels in each of the 4 groups. The TARC levels between the 4 groups did not show any difference (Table $3 b)$. Table 4 show the EASI scores and TARC levels of babies who were diagnosed with $\mathrm{AD}$ at 9 months of age. Comparison of serum TARC levels at 9 months did not show any difference between the groups in all babies or in those who developed AD. The EASI scores showed that most of the babies who developed AD at 9 months had mild disease, while 5 of the total 49 babies with AD had moderate disease. The overall highest EASI score was 13.6. The median scores did not differ significantly among the groups (Table 4).

The prevalence of FA at 1 year of age did not show any difference between the 4 groups. Sensitization to any food or inhalant allergen at 9 months of age was also not different between the 4 groups (Table 5). We 
Table 2. Incidence of AD

Risk, $n$ Cases of AD at 1 year, $n(\%)$

\begin{tabular}{lrr} 
a. Cumulative incidence of AD at 1 year & \\
Skin care and synbiotics (group 1) & 113 & $35(30.9)$ \\
Synbiotics (group 2) & 109 & $35(32.1)$ \\
Skin care (group 3) & 120 & $46(38.3)$ \\
No intervention (group 4) & 117 & $30(25.6)$ \\
\hline Total & 459 & $146(31.8)$ \\
\hline
\end{tabular}

b. Incidence of AD at 1 year according to the UKWP diagnostic criteria

\begin{tabular}{lll}
\hline Skin care and synbiotics (group 1) & 113 & $23(20.4)$ \\
Synbiotics (group 2) & 109 & $16(17.4)$ \\
Skin care (group 3) & 120 & $25(20.8)$ \\
No intervention (group 4) & 117 & $22(18.8)$ \\
\hline Total & 459 & $86(18.7)$ \\
\hline
\end{tabular}

c. Comparison of incidence of $\mathrm{AD}$ between groups according to different diagnostic criteria

\begin{tabular}{|c|c|c|}
\hline \multirow[t]{2}{*}{ Group } & \multicolumn{2}{|l|}{ Incidence of $\mathrm{AD}$ at 1 year } \\
\hline & $\begin{array}{l}\text { according to Japanese } \\
\text { Dermatological } \\
\text { Association guidelines } \\
\text { (cumulative) }-p \text { value }\end{array}$ & $\begin{array}{l}\text { according to UKWP } \\
\text { guidelines }-p \text { value }\end{array}$ \\
\hline 1 vs. 2 & 1 & 0.2936 \\
\hline 1 vs. 3 & 0.2704 & 1 \\
\hline 1 vs. 4 & 0.3834 & 0.8682 \\
\hline 2 vs. 3 & 0.3337 & 0.2312 \\
\hline 2 vs. 4 & 0.3058 & 0.4778 \\
\hline 3 vs. 4 & 0.037 & 0.7452 \\
\hline
\end{tabular}

All $p$ values were calcluated using the Fisher's exact test.

AD, atopic dermatitis; UKWP, U.K. Working Party's.

assessed allergen-specific IgE levels defining sensitization as class $\geq 1$ or class $\geq 2$, both of which showed no difference in the incidence of $\mathrm{AD}$ among groups (Table $6)$.

\section{Discussion}

In this study, we looked at the efficacy of emollients and synbiotics in preventing the development of $\mathrm{AD}$ at 1 year of age. Contrary to our expectations, we found that emollients and synbiotics, alone or in combination, did not prevent the development of $\mathrm{AD}$ or the sensitization to food and aeroallergens in this study.
Although we only report the questionnaire-based incidence of $\mathrm{AD}$ at 1 year here, the incidence of $\mathrm{AD}$ at 9 months of age assessed by a pediatrician and a dermatologist did not show any difference between the 4 groups (data not shown). Furthermore, we could not find any difference in severity of AD such as EASI and serum TARC levels as well as FA prevalence and allergen sensitization.

To understand the significance of the findings in this study, it is necessary to draw comparison between similar studies. This study differs from other studies with respect to the study population, primary endpoint, the definition of $\mathrm{AD}$, and the emollient application technique. This study followed a population of children who were at regular risk of developing AD while the other studies looked at populations at high risk $[3,16,17]$. The previous studies reported an incidence of $43-45 \%$ in control groups $[16,17]$, while in the present study the incidence was only $25.6 \%$. The difference in the backgrounds of the populations studied may be one of the important reasons for the observed difference in results.

The criteria used for the diagnosis of $\mathrm{AD}$ also differ between the studies. Simpson et al. defined a case of AD as a case of eczema occurring at any time of the intervention period [16], while Horimukai et al. defined a case as a pruritic skin condition of at least 2 weeks duration [17]. The PEBBLES study also defined a case as an itchy skin condition in the last 12 months [3]. On the contrary, the present study defined a case as an itchy skin condition lasting over 2 months. There is a possibility that the longer duration used to define a case, may have led to an underestimation of cases and given an overall lower incidence. The previous 3 studies considered the cases that occurred during the period of emollient application (6-8 months) while this study mainly focused on the lasting effect of emollient application 3-6 months following the cessation of any intervention that may partly account for the difference in outcome. Also, the number of children who did not have a family history of allergy was higher in the no intervention group, although not significantly. This could also be a reason for the significantly higher cumulative incidence of $\mathrm{AD}$ in the skin care only group.

Although the duration of emollient application did not greatly differ between the studies, the methods of emollient application may have differed. In this study, caregivers were advised to apply emollient at least on the cheeks and the peri-oral region as we hypothesized that protection of the skin barrier in this area could prevent sensitization to food allergens. The application of 
Table 3. Serum TARC levels in all infants and comparison between groups a. Serum TARC levels in all infants (in $\mathrm{pg} / \mathrm{mL}$ )

\begin{tabular}{lcccc}
\hline & $\begin{array}{l}\text { Skin care }+ \\
\text { synbiotics } \\
\text { (group 1) }\end{array}$ & $\begin{array}{l}\text { Synbiotics } \\
\text { (group 2) }\end{array}$ & $\begin{array}{l}\text { Skin care } \\
\text { (group 3) }\end{array}$ & $\begin{array}{l}\text { No intervention } \\
\text { (group 4) }\end{array}$ \\
\hline Number & 112 & 107 & 120 & 115 \\
Mean \pm SD & $1,118 \pm 858.5$ & $1,164 \pm 957.9$ & $1,214 \pm 974.9$ & $1,047 \pm 622.4$ \\
$95 \%$ CI lower, upper & $957.2-1,279$ & $980.5-1,347$ & $1,038-1,391$ & $931.6-1,162$ \\
Range, min, max & $261-5,733$ & $276-6,403$ & $138-6,039$ & $125-3,442$ \\
\hline
\end{tabular}

b. Comparison of serum TARC levels between groups

\begin{tabular}{lll}
\hline Group & $\begin{array}{l}p \text { value } \\
\text { (adjusted) }\end{array}$ & $\begin{array}{l}p \text { value } \\
\text { (unadjusted) }\end{array}$ \\
\hline & & \\
1 vs. 2 & 0.979 & 0.6926 \\
1 vs. 3 & 0.8302 & 0.3956 \\
1 vs. 4 & 0.9253 & 0.5348 \\
2 vs. 3 & 0.9718 & 0.6615 \\
2 vs. 4 & 0.7425 & 0.3121 \\
3 vs. 4 & 0.4455 & 0.1374 \\
\hline
\end{tabular}

All $p$ values were calculated using ANOVA and adjusted using the Tukey-Kramer method.

TRAC, thymus and activation-regulated chemokine.

Table 4. EASI score and TARC in infants diagnosed with $\mathrm{AD}$ at 9 months

\begin{tabular}{lcccc}
\hline & $\begin{array}{l}\text { Skin care }+ \\
\text { synbiotics } \\
\text { (group 1) }\end{array}$ & $\begin{array}{l}\text { Synbiotics } \\
\text { (group 2) }\end{array}$ & $\begin{array}{c}\text { Skin care } \\
\text { (group 3) }\end{array}$ & $\begin{array}{l}\text { No intervention } \\
\text { (group 4) }\end{array}$ \\
\hline EASI score & & & 15 & 13 \\
$\quad$ Number & 12 & 9 & 3.6 & 2.4 \\
Median & 0.8 & 1.2 & $1.8-5.6$ & $0.2-11.3$ \\
Range, min, max & $0.0-10.3$ & $0.4-13.6$ & 15 & 13 \\
Serum TARC concentration, pg/mL & 12 & 9 & 1,469 & 846 \\
$\quad$ Number & $1,088.5$ & 1,442 & $241.0-6,039.0$ & $125.0-2,601.0$ \\
Median & $483.0-4,038.0$ & $440.0-6,403.0$ & & \\
Range, min, max & & & & \\
\hline
\end{tabular}

TRAC, thymus and activation-regulated chemokine; $\mathrm{AD}$, atopic dermatitis.

emollient on other areas of the body was not prohibited, which may have led to a biased outcome as the total area of application may have varied from infant to infant. Therefore, instructions for thorough moisturizing of the baby's body may increase the benefits of the intervention.

In this study, due to ethical reasons, we did not prohibit the application of moisturizers in the no-intervention group. As this could mask the effect of the moistur- izer used as an intervention, we looked at the effect of any emollient (irrespective of the formal intervention assigned) on the development of AD. We did not observe any difference in incidence between children who received any type of emollient vs. those who did not (data not shown). This may suggest that emollients, by themselves, are not effective in preventing $\mathrm{AD}$ in the absence of other skin barrier protective measures. In addition, these results might also have been affected by deficiencies 
Table 5. Prevalence of FA at 1 year and sensitization to food and inhalant allergens at 9 months

\begin{tabular}{|c|c|c|c|c|}
\hline & $\begin{array}{l}\text { Skin care }+ \text { synbiotics } \\
\text { (group 1), } n(\%)\end{array}$ & $\begin{array}{l}\text { Synbiotics } \\
\text { (group 2), } n(\%)\end{array}$ & $\begin{array}{l}\text { Skin care } \\
\text { (group 3), } n(\%)\end{array}$ & $\begin{array}{l}\text { No intervention } \\
\text { (group 4), } n(\%)\end{array}$ \\
\hline \multicolumn{5}{|l|}{ FA } \\
\hline Present & $12(10.8)$ & $15(13.9)$ & $13(11.0)$ & $15(13.0)$ \\
\hline \multicolumn{5}{|c|}{ Food allergen sensitization } \\
\hline Absent & $54(48.2)$ & $49(45.4)$ & $47(39.5)$ & $62(53.9)$ \\
\hline \multicolumn{5}{|c|}{ Inhalation allergen sensitization } \\
\hline Absent & $99(89.2)$ & $100(92.6)$ & $108(90.8)$ & $104(90.4)$ \\
\hline Present & $12(10.8)$ & $8(7.4)$ & $11(9.2)$ & $11(9.6)$ \\
\hline
\end{tabular}

Table 6. Sensitization to food and inhaled allergens

\begin{tabular}{|c|c|c|c|c|c|c|c|c|c|c|}
\hline & \multicolumn{2}{|c|}{ Egg white } & \multicolumn{2}{|l|}{ Milk } & \multicolumn{2}{|c|}{ Ovomucoid } & \multicolumn{2}{|c|}{ House dust mite } & \multicolumn{2}{|l|}{ Cat } \\
\hline & $\begin{array}{l}\text { raw } \\
p \text { value }\end{array}$ & $\begin{array}{l}\text { adjusted } \\
p \text { value }\end{array}$ & $\begin{array}{l}\text { raw } \\
p \text { value }\end{array}$ & $\begin{array}{l}\text { adjusted } \\
p \text { value }\end{array}$ & $\begin{array}{l}\text { raw } \\
p \text { value }\end{array}$ & $\begin{array}{l}\text { adjusted } \\
p \text { value }\end{array}$ & $\begin{array}{l}\text { raw } \\
p \text { value }\end{array}$ & $\begin{array}{l}\text { adjusted } \\
p \text { value }\end{array}$ & $\begin{array}{l}\text { raw } \\
p \text { value }\end{array}$ & $\begin{array}{l}\text { adjusted } \\
p \text { value }\end{array}$ \\
\hline \multicolumn{11}{|c|}{ Allergen sensitization: no $=$ class 0, yes $=$ class $\geq 1$} \\
\hline 1 and 2 & 0.8941 & 1.0000 & 0.0638 & 0.3188 & 0.3799 & 1.0000 & 1.0000 & 1.0000 & 0.5706 & 1.0000 \\
\hline 1 and 3 & 0.2410 & 1.0000 & 0.0489 & 0.2937 & 0.1356 & 0.6778 & 0.5723 & 1.0000 & 0.2426 & 1.0000 \\
\hline 2 and 4 & 0.3497 & 1.0000 & 0.3330 & 1.0000 & 0.2851 & 1.0000 & 0.3773 & 1.0000 & 0.4881 & 1.0000 \\
\hline 3 and 4 & 0.0505 & 0.3028 & 0.2639 & 1.0000 & 0.0939 & 0.5631 & 1.0000 & 1.0000 & 1.0000 & 1.0000 \\
\hline \multicolumn{11}{|c|}{ Allergen sensitization: no $=$ class $0-1$, yes $=$ class $\geq 2$} \\
\hline 1 and 2 & 0.4935 & 1.0000 & 0.0130 & 0.0782 & 0.4048 & 1.0000 & 1.0000 & 1.0000 & 1.0000 & 1.0000 \\
\hline 1 and 3 & 0.0650 & 0.3901 & 0.2560 & 1.0000 & 0.0426 & 0.2558 & 0.7497 & 1.0000 & 0.3217 & 1.0000 \\
\hline
\end{tabular}

All $p$ values were calculated using Fisher's exact test and adjusted using the Holm method.

in the reporting of data, underestimation of $\mathrm{AD}$ occurrence, and the overestimation of the effect of interventions. Further studies are needed to verify the prevalence of $\mathrm{AD}$ by 1 year of age and also to re-evaluate the emollient application methods.

Administration of synbiotics to the mother during pregnancy and breastfeeding, and then to the infant after birth may be more beneficial as opposed to administration during pregnancy and breastfeeding or, as in our study, to the infant only $[6,18]$. This importance is highlighted by the findings that the maternal microbiome is transferred to the fetus during pregnancy, as microbial DNA has been isolated from all feto-maternal compart- ments including the amniotic fluid, umbilical cord blood, and meconium [19].

Conventionally, several species of Bifidobacteria have been administered for establishing normal intestinal bacterial flora of premature infants and newborns, and the safety of Bifidobacterium bifidum strain OLB 6378 used in this study has already been established [20]. Although we only used one bacterial species here, as the microbial composition of the gut is diverse, using several species and multiple strains of probiotic bacteria may also result in more physiological colonization. This is supported by evidence that shows that Lactobacilli and Bifidobacteria act synergistically in a species-specific manner and also 
that a combination of probiotics may be more effective in the overall maturation of the immune system [21, 22]. Therefore, it needs to be iterated that identifying synergistic bacterial species and prebiotics that fuel their function is important as microbial metabolites such as butyrate have shown importance in building a tolerogenic environment [23].

Here we report the initial findings from an interventional study using skin emollients and synbiotics for the prevention of AD in infancy. As far as the evidence from this study shows, the application of emollients and synbiotics may not suffice to prevent the development of $\mathrm{AD}$ and allergen sensitization in the normal population. Nevertheless, although here we only report results at 1 year of age, we are continuing to collect data on long-term effects of synbiotics and skin care on the development of $\mathrm{AD}$ and other allergic diseases.

\section{Acknowledgements}

We wish to thank Miho Watanabe and the staff at Katsushika Red Cross Hospital for their help in recruiting participants and coordinating the study. We also thank the study participants for their cooperation.

\section{Statement of Ethics}

The parents or guardians provided written consent to participate in the study. The study protocol was approved by the Chiba University Ethics Committee (reference no. 2067).

\section{Disclosure Statement}

The authors have no conflicts of interest to disclose.

\section{Funding Sources}

This study was supported by the Environmental Restoration and Conservation Agency of Japan in fiscal years 2014-2016 and grants from the Japan Agency for Medical Research and Development (AMED-CREST) (15652274).

\section{Author Contributions}

E.D.: analyzed data and wrote the manuscript. Yumi Tani, M.S., and C.M.: examined children and collected the data and biospecimens. K.N.: did statistical analysis and wrote the manuscript. Yaei Togawa: evaluated the skin conditions of the children independently. Y.S., H.O., and N.S.: designed the study, collected the data. T.N. and F.Y.: critically reviewed the manuscript.

\section{References}

1 Jungersted JM, Scheer H, Mempel M, Baurecht $\mathrm{H}$, Cifuentes L, Høgh JK, et al. Stratum corneum lipids, skin barrier function and filaggrin mutations in patients with atopic eczema. Allergy. 2010 Jul;65(7):911-8.

2 Lowe AJ, Tang ML, Dharmage SC, Varigos G, Forster D, Gurrin LC, et al. A phase I study of daily treatment with a ceramide-dominant triple lipid mixture commencing in neonates. BMC Dermatol. 2012 Apr;12(1):3.

3 Lowe AJ, Su JC, Allen KJ, Abramson MJ, Cranswick N, Robertson CF, et al. A randomized trial of a barrier lipid replacement strategy for the prevention of atopic dermatitis and allergic sensitisation: The PEBBLES Pilot Study. Br J Dermatol. 2018 Jan;178(1):e1921.

4 Weidinger S, Novak N. Atopic dermatitis. Lancet. 2016 Mar;387(10023):1109-22.

5 Food and Agriculture Organization of the United Nations WHO. Probiotics in food: health and nutritional properties and guidelines for evaluation. Rome: Food and Agriculture Organization of the United Nations: World Health Organization; 2006.

6 Panduru M, Panduru NM, Sălăvăstru CM, Tiplica GS. Probiotics and primary prevention of atopic dermatitis: a meta-analysis of randomized controlled studies. J Eur Acad Dermatol Venereol. 2015 Feb;29(2): 232-42.

7 Fiocchi A, Pawankar R, Cuello-Garcia C, Ahn K, Al-Hammadi S, Agarwal A, et al. World Allergy Organization-McMaster University Guidelines for Allergic Disease Prevention (GLAD-P): probiotics. World Allergy Organ J. 2015 Jan;8(1):4.

8 Gibson GR, Roberfroid MB. Dietary modulation of the human colonic microbiota: introducing the concept of prebiotics. J Nutr. 1995 Jun;125(6): 1401-12.

9 Moro G, Arslanoglu S, Stahl B, Jelinek J, Wahn U, Boehm G. A mixture of prebiotic oligosaccharides reduces the incidence of atopic dermatitis during the first six months of age. Arch Dis Child. 2006 Oct;91(10):8149.

10 Boženský J, Hill M, Zelenka R, Skýba T. Prebiotics Do Not Influence the Severity of Atopic Dermatitis in Infants: A Randomised Controlled Trial. PLoS One. 2015 Nov; 10(11):e0142897.

11 Chang YS, Trivedi MK, Jha A, Lin YF, Dimaano L, García-Romero MT. Synbiotics for Prevention and Treatment of Atopic Dermatitis: A Meta-analysis of Randomized Clinical Trials. JAMA Pediatr. 2016 Mar;170(3):236-42.
12 Katayama I, Aihara M, Ohya Y, Saeki H, Shimojo N, Shoji S, et al.; Japanese Society of Allergology. Japanese guidelines for atopic dermatitis 2017. Allergol Int. 2017 Apr;66(2): 230-47.

13 Williams HC, Burney PG, Hay RJ, Archer CB, Shipley MJ, Hunter JJ, et al. The U.K. Working Party's Diagnostic Criteria for Atopic Dermatitis. I. Derivation of a minimum set of discriminators for atopic dermatitis. Br J Dermatol. 1994 Sep;131(3): 383-96.

14 Williams HC, Burney PG, Strachan D, Hay RJ. The U.K. Working Party's Diagnostic Criteria for Atopic Dermatitis. II. Observer variation of clinical diagnosis and signs of atopic dermatitis. Br J Dermatol. 1994 Sep;131(3): 397-405.

15 Williams HC, Burney PG, Pembroke AC, Hay RJ. The U.K. Working Party's Diagnostic Criteria for Atopic Dermatitis. III. Independent hospital validation. Br J Dermatol. 1994 Sep; 131(3):406-16.

16 Simpson EL, Chalmers JR, Hanifin JM, Thomas KS, Cork MJ, McLean WH, et al. Emollient enhancement of the skin barrier from birth offers effective atopic dermatitis prevention. J Allergy Clin Immunol. 2014 Oct;134(4):818-23. 
17 Horimukai K, Morita K, Narita M, Kondo M, Kitazawa $\mathrm{H}$, Nozaki M, et al. Application of moisturizer to neonates prevents development of atopic dermatitis. J Allergy Clin Immunol. 2014 Oct;134(4):824-830.e6.

18 Wickens K, Barthow C, Mitchell EA, Stanley TV, Purdie G, Rowden J, et al. Maternal supplementation alone with Lactobacillus rhamnosus HN001 during pregnancy and breastfeeding does not reduce infant eczema. Pediatr Allergy Immunol. 2018 May;29(3):296-302.
19 West CE, Jenmalm MC, Prescott SL. The gut microbiota and its role in the development of allergic disease: a wider perspective. Clin Exp Allergy. 2015 Jan;45(1):43-53.

20 Ganguli K, Walker WA. Probiotics in the prevention of necrotizing enterocolitis. J Clin Gastroenterol. 2011 Nov;45 Suppl:S133-8.

21 Ouwehand AC, Isolauri E, Kirjavainen PV, Tölkko S, Salminen SJ. The mucus binding of Bifidobacterium lactis Bb12 is enhanced in the presence of Lactobacillus GG and Lact. delbrueckii subsp. bulgaricus. Lett Appl Microbiol. 2000 Jan;30(1):10-3.
22 Zuccotti G, Meneghin F, Aceti A, Barone G, Callegari ML, Di Mauro A, et al.; Italian Society of Neonatology. Probiotics for prevention of atopic diseases in infants: systematic review and meta-analysis. Allergy. 2015 Nov;70(11): 1356-71.

23 Furusawa Y, Obata Y, Fukuda S, Endo TA, Nakato G, Takahashi D, et al. Commensal microbe-derived butyrate induces the differentiation of colonic regulatory T cells. Nature. 2013 Dec;504(7480):446-50. 